\title{
Toxicity of Neurons Treated with Herbicides and Neuroprotection by Mitochondria-Targeted Antioxidant SS31
}

Tejaswini P. Reddy ${ }^{1}$, Maria Manczak ${ }^{1}$, Marcus J. Calkins ${ }^{1}$, Peizhong Mao ${ }^{1}$, Arubala P. $\operatorname{Reddy}^{1}$, Ulziibat Shirendeb ${ }^{1}$, Byung Park ${ }^{2}$ and P. Hemachandra Reddy ${ }^{1,3, *}$

1 Neurogenetics Laboratory, Division of Neuroscience, Oregon National Primate Research Center, Oregon Health \& Science University, 505 NW 185th Avenue, Beaverton, OR 97006, USA;

E-Mails: tejaswinireddy99@gmail.com (T.P.R.); manczakm@ohsu.edu (M.M.); calkinsm@ohsu.edu (M.J.C.); maop@ohsu.edu (P.M.); reddya@ ohsu.edu (A.P.R.); shirende@ohsu.edu (U.S.)

2 Division of Biostatistics, Department of Public Health and Preventive Medicine, Oregon Health \& Science University, 3181 SW Sam Jackson Park Road, Portland, OR 97239, USA; E-Mail: parkb@ohsu.edu

3 Department of Physiology and Pharmacology, Oregon Health \& Science University, 3181 SW Sam Jackson Park Road, Portland, OR 97239, USA

* Author to whom correspondence should be addressed; E-Mail: reddyh@ohsu.edu; Tel.: +1-503-418-2625; Fax: +1-503-418-2701.

Received: 31 December 2010; in revised form: 13 January 2011 / Accepted: 17 January 2011 / Published: 19 January 2011

\begin{abstract}
The purpose of this study was to determine the neurotoxicity of two commonly used herbicides: picloram and triclopyr and the neuroprotective effects of the mitochondria-targeted antioxidant, SS31. Using mouse neuroblastoma (N2a) cells and primary neurons from C57BL/6 mice, we investigated the toxicity of these herbicides, and protective effects of SS1 peptide against picloram and triclopyr toxicity. We measured total RNA content, cell viability and mRNA expression of peroxiredoxins, neuroprotective genes, mitochondrial- encoded electron transport chain (ETC) genes in N2a cells treated with herbicides and SS31. Using primary neurons from C57BL/6 mice, neuronal survival was studied in neurons treated with herbicides, in neurons pretreated with SS31 plus treated with herbicides, neurons treated with SS31 alone, and untreated neurons. Significantly decreased total RNA content, and cell viability in N2a cells treated with picloram and triclopyr were found compared to untreated N2a cells. Decreased mRNA
\end{abstract}


expression of neuroprotective genes, and ETC genes in cells treated with herbicides was found compared to untreated cells. Decreased mRNA expression of peroxiredoxins 1-6 in $\mathrm{N} 2 \mathrm{a}$ cells treated with picloram was found, suggesting that picloram affects the antioxidant enzymes in N2a cells. Immunofluorescence analysis of primary neurons revealed that decreased neuronal branching and degenerating neurons in neurons treated with picloram and triclopyr. However, neurons pretreated with SS31 prevented degenerative process caused by herbicides. Based on these results, we propose that herbicides-picloram and triclopyr appear to damage neurons, and the SS31 peptide appears to protect neurons from herbicide toxicity.

Keywords: Mitochondria-targeted antioxidant; herbicides; Picloram; Triclopyr; Szeto-Schiller peptide 31; mouse neuroblastoma cells; mouse primary hippocampal neurons; electron transport chain; oxidative stress

\section{Introduction}

Artificially synthesized, contact and systemic herbicides are widely used in the agricultural sector and in landscape turf management to prevent the growth of unwanted plants. Contact herbicides, such as paraquat, are fast-acting and destroy plant tissue upon contact. Systemic herbicides, such as glyphosate, are slow-acting and kill plants through the vascular system. Although synthesized herbicides are designed to target unwanted plants, many end up affecting other living species, including other plants, insects, rodents, and humans [1]. The side effects of these chemicals on living species, particularly on humans, are not well understood.

Recent studies have reported that commonly used herbicides and pesticides adversely affect humans [2-12]. For example, humans exposed to the herbicide paraquat have shown symptoms similar to those of Parkinson's disease [11]. Paraquat is artificially synthesized, similar to the analgesic drug 1-methyl-4-phenyl-1,2,3,6-tetrahydro pyridine (MPTP), which metabolizes into 1-methyl-4-phenylpyridinium $\left(\mathrm{MPP}^{+}\right)$, a chemical implicated in the development of Parkinson's disease [13]. Many other artificially synthesized herbicides have also shown carcinogenic, mutagenic, and teratogenic effects on mammals, including humans.

The current study focused on the systemic, slow-acting herbicides picloram and triclopyr, which are among the most commonly used herbicides in the world [14-22]. Picloram (4-amino-3,5,6,-trichloropicolinic acid) is widely used for broadleaf and woody plant control. It comes from the pyridine family of compounds and is used in such open areas as pastures, rangelands, and forests [23]. Picloram is the active ingredient in weed-control products Tordon and Grazon [17-20]. Historically, picloram was infamously known for being mixed with 2,4-D to create Agent White, a defioliant used in the Vietnam War for plants that survived the toxicity of Agent Orange (2,4-D and 2,4,5-T). Agent Orange was found to have carcinogenic, mutagenic, and teratogenic effects on large human populations exposed to it [24]. Although picloram is understood to be a carcinogen [25], little is known about mechanisms of its neurotoxic effects on humans. 
Triclopyr (3,5,6-trichloro-2-pyridinyloxyacetic acid) is the active ingredient in Garlon herbicides. Similar to picloram, triclopyr is also used widely for broadleaf and woody plant control. Triclopyr is a foliar systemic herbicide from the pyridine group of herbicides. It is known to have severe toxic effects on humans [14-16,21,22] and to have moderate toxicity in rat models [26].

Very little is known about the toxic and adverse effects of herbicides such as picloram and triclopyr, to the brain cells of rodents and humans. In the present study, we studied toxicity of herbicides using mouse neuroblastoma cells and primary neurons from C57BL/6 mice. Using N2a cells, we measured: (1) the total RNA content, (2) mRNA expression of genes that encode antioxidant enzymes-peroxiredoxins 1-6, neuroprotective genes (PGC1 $\alpha$, FOXO1, and NMDA receptor), and mitochondrial-encoded ETC genes (NADH subunit 1-complex I, cytochrome B (Cyt. B)-complex III, cytochrome c oxidase 1-complex IV, and ATPase 6-complex V, and (3) cell viability-in N2a cells treated and untreated with the herbicides and in N2a cells pretreated with SS31 and then treated with herbicides and also N2a cells treated with SS31. Using primary neurons from C57BL6 mice, we studied neurite outgrowth and neuronal survival: (1) in primary neurons treated with herbicides, (2) in primary neurons pretreated with mitochondria-targeted antioxidant SS31 plus treated with herbicides, (3) primary neurons treated with SS31, and (4) untreated primary neurons.

\section{Materials and Methods}

SS31 peptide: We purchased the SS31 peptide, a mitochondria-targeted antioxidant, from AnaSpec, CA. The SS31 tetra-peptide was originally synthesized by Dr. Hazel H. Szeto in collaboration with Dr. Peter W. Schiller. Drs. Szeto and Schiller designed and synthesized four different peptides (SS31, SS02, SS20, and SS19) with the amino acids Dmt, D-Arg, Phe, and Lys, and with the Dmt residue [27]. The peptide SS31 was chosen for our study because it targets mitochondria and penetrates into cells and the mitochondria several hundred times [27]. When the SS31 peptide penetrates into mitochondria, tyrosine (Tyr) and dimethyltyrosine (Dmt) analogs from the peptides scavenge and diminish free radicals, such as $\mathrm{H}_{2} \mathrm{O}_{2}, \mathrm{OH}$, and ONOO [27-29]. SS31 also prevents lipid peroxidation [27-29]. At low molar concentrations (e.g., $1 \mathrm{nM}$ ), SS31 is reported to protect mammalian cells, including neurons, from mitochondrial and other toxic insults [30]. Therefore, we used a $1 \mathrm{nM}$ final concentration of SS31 in this study.

Reagents and chemicals: We purchased and prepared a phosphate buffer saline (Invitrogen, CA), trypsin EDTA (Invitrogen), N2a media (1:1 of DMEM and OPTI-MEM, 1x Penicillin/Streptomycin, 5\% Fetal Bovine Serum), picloram (Sigma-Aldrich, CA), triclopyr and MTT (Sigma-Aldrich, CA), Trizol (Invitrogen), chloroform, isopropyl alcohol, DEPC (Sigma-Aldrich).

Primary neuronal cultures: The C57BL/6 mice were housed at the Oregon National Primate Research Center of Oregon Health \& Science University (OHSU). They were originally purchased from Taconic Farms and then bred in our animal facility. The OHSU Institutional Animal Care and Use Committee approved all procedures for animal care according to guidelines set forth by the National Institutes of Health.

Primary neuronal cultures from these mice were prepared using methods described by Manczak et al. [30]. Briefly, mice postnatal day 1 were decapitated, and the brains were removed and placed in a room-temperature Hibernate ${ }^{\circledR}$-A medium (Brain Bits, Springfield IL) supplemented with 
B-27 (Invitrogen) and 0.5mM GlutaMAX ${ }^{\mathrm{TM}}$ (Invitrogen). The hippocampus was then dissected for culturing. Hippocampus pairs from individual mice were minced into pieces less than $1 \mathrm{~mm}^{3}$ and transferred to a solution of papain $(2 \mathrm{mg} / \mathrm{mL}$; Worthington Biochemical Corp, Lakewood, NJ) that was dissolved in Hibernate ${ }^{\circledR}-\mathrm{A}$ without calcium, but supplemented with $0.5 \mathrm{mM}$ GlutaMAX ${ }^{\mathrm{TM}}$. The tissue was digested for $30 \mathrm{~min}$ in a shaking water bath at $30{ }^{\circ} \mathrm{C}$. Digested tissue was then removed to $2 \mathrm{~mL}$ HABG and triturated 10 times with a fire-polished, siliconized (Sigmacote; Sigma, St. Louis MO), 9 in glass pipette. Samples were allowed to settle by gravity for about $1 \mathrm{~min}$. Then the supernatant containing dissociated neurons was removed to a fresh tube. An additional $2 \mathrm{~mL}$ HABG was added to the pellet, and the process was repeated until $6 \mathrm{~mL}$ dissociated neurons were collected. Neurons were centrifuged at $200 \mathrm{~g}$ for $2 \mathrm{~min}$ and then washed with $2 \mathrm{~mL} \mathrm{HABG}$. The pellets were resuspended in $2 \mathrm{~mL}$ Neurobasal ${ }^{\mathrm{TM}}$ (Invitrogen) supplemented with B-27 and $0.5 \mathrm{mM}^{-}$GlutaMAX $^{\mathrm{TM}}$ (growth medium). The neurons were counted, plated at 500 neurons $/ \mathrm{mm}^{2}$ on poly-D-lysine-coated coverslips, and placed into a $37{ }^{\circ} \mathrm{C}$ incubator at $5 \% \mathrm{CO}_{2}$. One hr after plating, the growth medium was completely replaced. After 3 days in vitro and every 2 days thereafter for 10 days, one-half of the growth medium was changed.

Treatment with mitochondria-targeted antioxidant SS31 and herbicides: One group of postnatal day 1 primary (cortical and hippocampal) neurons from C57BL/6 mice remained untreated, and others groups were treated with SS31 $(1 \mathrm{nM})$, picloram $(5 \mathrm{mM})$ triclopyr $(3 \mathrm{mM})$ and were used for experiments. To determine the preventive effects herbicide toxicity, we pretreated with SS31 (1 nM) for $6 \mathrm{~h}$, and then treated with picloram $(5 \mathrm{mM})$ and triclopyr $(3 \mathrm{mM})$ for $48 \mathrm{~h}$, and studied neurodegeneration or neuronal survival using a neuronal marker-Beta III tubulin. After the treatments, cells on coverslips were washed with warm PBS and then fixed in freshly prepared 4\% paraformaldehyde in PBS for 10-15 minutes. Cells were then washed with PBS and permeabilized with $0.1 \%$ Triton-X100 in PBS. All incubations were performed in a humidified chamber. The cells were blocked with $1 \%$ blocking solution (Invitrogen) for $1 \mathrm{~h}$ at room temperature. The primary antibody for beta-III tubulin was diluted in a blocking solution 1:2,000 and incubated at room temperature for $2 \mathrm{~h}$. The cells were then washed 3 times for 5 min with PBS. Alexa Fluor® 568 goat anti-mouse (Invitrogen), a secondary antibody, was diluted 1:500 in a blocking solution, and was then applied to the cells for $1 \mathrm{~h}$ at room temperature. The cells on the coverslips were washed 2 times for 10 min with PBS and then mounted onto glass slides using the mounting medium Prolong Gold (Invitrogen). The slides were allowed to dry for at least $24 \mathrm{~h}$, and then we took images of cells, using a Zeiss widefield microscope with a 100x oil immersion lens.

Mouse neuroblastoma cells: We studied the effects of herbicides on N2a cells, purchased from American Type Culture Collection (ATCC, Manassas, VA).

Figure 1 illustrates the experimental strategy of our cell culture work, including treatments, number of cells per control (untreated N2a cells) and experimental groups (N2a cells treated with herbicides alone, and N2a cells pretreated with mitochondrial targeted antioxidant SS31 and then treated with herbicides), the number of replicates per experiment, and the number of experiments. As shown in Figure 1, half a million N2a cells were suspended per well into six-well plates. The cells were grown in a medium (1:1 DMEM and MEM, 5\% FBS, 1x penicillin, and streptomycin) until 80\% confluence in six-well plates. Then we treated them with a serum-free medium containing picloram $(5 \mathrm{mM})$ and triclopyr ( $3 \mathrm{mM})$. In preliminary studies, the N2a cells started exhibiting signs of cell death, including 
losing projections, shrunken, and detaching from the surface of the flask, at a treatment dose of $5 \mathrm{mM}$ for picloram and $3 \mathrm{mM}$ for triclopyr. It is these concentrations that we used in our experiments.

Figure 1. Experimental strategy of mouse neuroblastoma (N2a) cells pretreated with SS31 and then treated with the herbicides picloram and triclopyr.

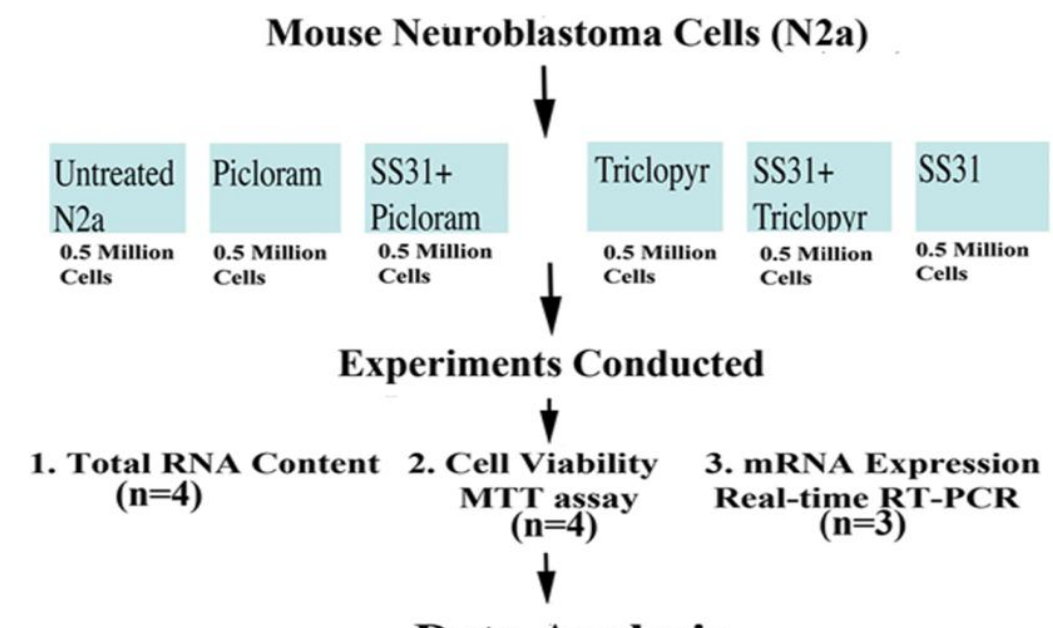

\section{Data Analysis}

To determine whether SS31 could protect the N2a cells from the toxicity of picloram and triclopyr, we pretreated them with SS31 (1 nM final concentration) in a serum-free medium) for $8 \mathrm{~h}$, and then with $5 \mathrm{mM}$ picloram and $3 \mathrm{mM}$ triclopyr for $48 \mathrm{hrs}$. After this period, we harvested the N2a cells for RNA analysis (total RNA content and mRNA expression of mitochondrial ETC genes and neuroprotective genes) and MTT (3-(4,5-dimethylthiazol-2-yl)-2,5-diphenyl tetrazolium bromide) assay.

RNA isolation: We isolated total RNA from the N2a cells: those cells that we had treated with picloram, those that were first pretreated with SS31 and then treated with picloram, those treated with triclopyr, those pretreated with SS31 and then treated with triclopyr, those treated with SS31 only, and those that were untreated. We used the standard TRIzol method to isolate RNA from all 8 samples. Briefly, tubes of $\mathrm{N} 2 \mathrm{a}$ cells were defrosted and resuspended in $50 \mu \mathrm{L}$ of PBS. One hundred $\mu \mathrm{L}$ of TRIzol was added to each tube, and the contents were mixed. One hundred $\mu \mathrm{L}$ of chloroform was then added to each tube, and the contents were mixed again. The tubes were centrifuged at 16,000 RPM, and the aqueous mixture was then transferred to newly labeled tubes. RNA was precipitated by the addition of 2 volumes of isopropyl alcohol. The tubes were centrifuged at 16,000 RPM, and the top layer of alcohol was discarded. The RNA pellet was washed with $70 \%$ alcohol. Ten $\mu \mathrm{L}$ DEPC-treated distilled water was added to each dried pellet. The optical density of each pellet was measured, to determine the RNA concentration.

cDNA synthesis: As described by Manczak et al. [31], we synthesized cDNA using RNA from all N2a cell preparations. Using SYBR-Green chemistry-based quantitative RT-PCR, we measured mRNA expression of antioxidant enzyme proteins, including Prx1, Prx2, Prx3, Prx4, Prx5, Prx6, neuroprotective genes (PGC1 $\alpha$, FOX1, and NMDAR); and mitochondrially encoded genes (NADH sub1, COX1, Cyt. B, and ATP-6) for all preparations. Briefly, $1 \mu \mathrm{g}$ DNAse-treated total RNA was used as starting material, to which we added the following: $1 \mu \mathrm{L}$ oligo (dT), $1 \mu \mathrm{L} 10 \mathrm{mM}$ dNTPs, $4 \mu \mathrm{L}$ $5 \times$ first-strand buffers, (4 $\mu \mathrm{L} 25 \mathrm{mM}) \mathrm{MgCl}_{2},(2 \mu \mathrm{L} 0.1 \mathrm{M})$ DTT, and $1 \mu \mathrm{L}$ RNAse out (Invitrogen). 
RNA, oligo (dT), and dNTPs were mixed first, heated at $65^{\circ} \mathrm{C}$ for $5 \mathrm{~min}$, and then chilled on ice until other components were added. The preparations were incubated at $42{ }^{\circ} \mathrm{C}$ for $2 \mathrm{~min}$. Then $1 \mu \mathrm{L}$ Superscript III (40 U/ $\mu \mathrm{L})$ (Invitrogen) was added to the preparations. They were incubated at $42{ }^{\circ} \mathrm{C}$ for $50 \mathrm{~min}$. The reaction in each preparation was inactivated by heating the contents at $70{ }^{\circ} \mathrm{C}$ for $15 \mathrm{~min}$.

Quantitative RT-PCR analysis: Using primer express software (Applied Biosystems), we designed the oligonucleotide primers for the housekeeping genes $\beta$-actin and GAPDH; for mRNA expression of genes that encode antioxidant enzyme proteins, including Prx1, Prx2, Prx3, Prx4, Prx5 and Prx6; for neuroprotective genes (PGC1 $\alpha$, FOX1 and NMDAR); and for mitochondrially encoded genes (NADH sub1, COX1, Cyt. B, and ATP-6) for all preparations of the herbicides studied. The primer sequences and amplicon sizes are listed in Table 1.

Quantitative RT-PCR amplification reactions were carried out in an ABI Prism 7,900 sequence detection system (Applied Biosystems), in a $25-\mu \mathrm{L}$ volume of total reaction mixture. The reaction mixture consisted of $1 \times$ PCR buffer containing SYBR-Green; $3 \mathrm{mM} \mathrm{MgCl}_{2} ; 100 \mathrm{nM}$ of each primer; $200 \mathrm{nM}$ each of dATP, dGTP, and dCTP; $400 \mathrm{nM}$ dUTP; $0.01 \mathrm{U} / \mu \mathrm{L}$ AmpErase UNG; and $0.05 \mathrm{U} / \mu \mathrm{L}$ AmpliTaq Gold (ABI). Twenty nanograms of cDNA template were added to each reaction mixture.

Table 1. Oligonucleotide primers used for real-time RT-PCR analysis.

\begin{tabular}{|c|c|c|}
\hline Gene & DNA Sequences $\left(5^{\prime}-3^{\prime}\right)$ & PCR Product Size \\
\hline \multicolumn{3}{|c|}{ Antioxidant Enzyme Proteins (Peroxiredoxins) } \\
\hline \multirow[t]{2}{*}{ Prx1 } & Forward Primer TGGCTCGACCCTGCTGATAG & 61 \\
\hline & Reverse Primer GGAGCAGGATACCCAATTTTTG & \\
\hline \multirow[t]{2}{*}{ Prx2 } & Forward Primer CCCCTGAATATCCCTCTGCTT & 57 \\
\hline & Reverse Primer CGCCGTAATTCTGGGACAA & \\
\hline \multirow[t]{2}{*}{ Prx3 } & Forward Primer GGCCCCATTTCTTGGAT & 60 \\
\hline & Reverse Primer CAGGGCAGGCTAAGGGAAAG & \\
\hline \multirow[t]{2}{*}{ Prx4 } & Forward Primer CCTGTTGCGGACCGAATCT & 55 \\
\hline & Reverse Primer GGGTCCGGAACCGTTCAT & \\
\hline \multirow[t]{2}{*}{ Prx5 } & Forward Primer CCCGATCAAGGTGGGAGAT & 56 \\
\hline & Reverse Primer CCCGGTTCCCCTTCAAATA & \\
\hline \multirow[t]{2}{*}{ Prx6 } & Forward Primer TCTGGCAAAAAATACCTCCGTTA & 58 \\
\hline & Reverse Primer GCCCCAATTTCCGCAAAG & \\
\hline \multicolumn{3}{|c|}{ Neuroprotective Genes } \\
\hline \multirow[t]{2}{*}{ FOXOs1 } & Forward Primer CCCGTCCTAGGCACGAACT & 69 \\
\hline & Reverse Primer ACGCGCCCAGAACTTAACTTC & \\
\hline \multirow[t]{2}{*}{ PGC1 $\alpha$} & Forward Primer GGACAGTCTCCCCGTGGAT & 57 \\
\hline & Reverse Primer TCCATCTGTCAGTGCATCAAATG & \\
\hline \multirow[t]{2}{*}{ NMDAR } & Forward Primer GGTCAGTTCTGTCCTGCACATC & 65 \\
\hline & Reverse Primer TGACTCTCCCGCGGAAAC & \\
\hline \multicolumn{3}{|c|}{ Mitochondrial Electron Transport Chain Genes } \\
\hline \multirow[t]{2}{*}{ Complex I-NADHsubunit1 } & Forward Primer CGGGCCCCCTTCGAC & 72 \\
\hline & Reverse Primer GGCCGGCTGCGTATTCT & \\
\hline \multirow[t]{2}{*}{ Complex II Cyt. B } & Forward Primer TTATCGCGGCCCTAGCAA & 70 \\
\hline & Reverse Primer TAATCCTGTTGGGTTGTTTGATCC & \\
\hline \multirow[t]{2}{*}{ Complex IV COX1 } & Forward Primer GAAGAGACAGTGTTTCATGTGGTGT & 75 \\
\hline & Reverse Primer TCCTGGGCCTTTCAGGAATA & \\
\hline
\end{tabular}


Table 1. Cont.

\begin{tabular}{|c|c|c|}
\hline Gene & DNA Sequences (5'-3') & PCR Product Size \\
\hline \multicolumn{3}{|c|}{ Mitochondrial Electron Transport Chain Genes } \\
\hline \multirow[t]{2}{*}{ Complex V ATPase-6 } & Forward Primer TGTGGAAGGAAGTGGGCAA & 73 \\
\hline & Reverse Primer CCACTATGAGCTGGAGCCGT & \\
\hline \multicolumn{3}{|c|}{ Housekeeping Genes } \\
\hline \multirow[t]{2}{*}{ Beta Actin } & Forward Primer ACGGCCAGGTCATCACTATTC & 65 \\
\hline & Reverse Primer AGGAAGGCTGGAAAAGAGCC & \\
\hline \multirow[t]{2}{*}{ GAPDH } & Forward Primer TTCCCGTTCAGCTCTGGG & 59 \\
\hline & Reverse Primer CCCTGCATCCACTGGTGC & \\
\hline
\end{tabular}

To determine the unregulated endogenous reference gene in N2a cells treated with herbicides, we tested GAPDH. The $\mathrm{C}_{\mathrm{T}}$-value - the cycle number at which the fluorescence generated within a reaction crosses the threshold within the linear phase of the amplification profile - is an important, quantitative parameter in RT-PCR analysis in the control and experimental samples because it determines the number of PCR cycles at which the PCR products start accumulating quantitatively in a real time [31]. All reactions were carried out in duplicate with a no template control. The PCR conditions were: $50{ }^{\circ} \mathrm{C}$ for $2 \mathrm{~min}, 95{ }^{\circ} \mathrm{C}$ for $10 \mathrm{~min}$, followed by 40 cycles of $95{ }^{\circ} \mathrm{C}$ for $15 \mathrm{~s}$, and $60{ }^{\circ} \mathrm{C}$ for $1 \mathrm{~min}$. The fluorescent spectra were recorded during the elongation phase of each PCR cycle. To distinguish specific amplicons from non-specific amplifications, a dissociation curve was generated. The $\mathrm{C}_{\mathrm{T}}$-values were calculated with the sequence-detection system (SDS) software V1.7 (Applied Biosystems) and with an automatic setting of base line, which was the average value of PCR from cycles 3-15, plus $\mathrm{C}_{\mathrm{T}}$ generated 10 times its standard deviation. The amplification plots and $\mathrm{C}_{\mathrm{T}}$-values were exported from the exponential phase of PCR directly into a Microsoft Excel worksheet for further analysis.

The mRNA transcript level was normalized against $\beta$-actin and GAPDH at each dilution. The standard curve was the normalized mRNA transcript level plotted against the log-value of the input cDNA concentration at each dilution. To quantify mRNA fold change, we used CT method of ABI [31]. Briefly, this method involved averaging duplicate samples taken as the $\mathrm{C}_{\mathrm{T}}$-values for $\beta$-actin, GAPDH, and neuroprotective and mitochondrial encoded genes. We used GAPDH normalization in the present study because GAPDH CT values were similar for all groups of cells treated with the herbicides for all groups first pretreated with SS31 and then treated with the herbicides. The $\Delta \mathrm{C}_{\mathrm{T}}$-value was obtained by subtracting the average GAPDH $\mathrm{C}_{\mathrm{T}}$-value from the average $\mathrm{C}_{\mathrm{T}}$-value of neuroprotective and mitochondrial-encoded genes and peroxiredoxins. The present study used the average $\Delta \mathrm{C}_{\mathrm{T}}$ of untreated $\mathrm{N} 2 \mathrm{a}$ cells as the calibrator. Fold change was calculated according to the formula $2^{-\left(\Delta \Delta \mathrm{C}_{\mathrm{T}}\right)}$, where $\Delta \Delta \mathrm{C}_{\mathrm{T}}$ was the difference between $\Delta \mathrm{C}_{\mathrm{T}}$ and the $\Delta \mathrm{C}_{\mathrm{T}}$ calibrator value [31].

MTT Assay: For cell viability of N2a cells treated with picloram and triclopyr, and for N2a cells first pre-treated with SS31 and then the herbicides, we used an MTT assay, as described by Mosmann [32]. The purpose of the MTT assay was to determine the mitochondrial dehydrogenase cleavage activity of MTT in the N2a cells treated with herbicides. Two hr of MTT treatment was enough to determine mitochondrial respiration [33,34]. Briefly, after treatment with the herbicides or pre-treatment with $\mathrm{SS} 31,50 \mu \mathrm{L}$ MTT assay solution $(5 \mathrm{mg} / \mathrm{mL})$ was added to each well. After $2 \mathrm{~h}$, the solutions were removed, and $1 \mathrm{~mL}$ lysis buffer (20\% SDS plus 50\% DMSO) was added to each well. The plate was 
shaken for $5 \mathrm{~min}$, and then the solutions were transferred to cuvettes. Blue Formosan, which was produced from MTT cleavage by active mitochondria dehydrogenase and dissolved in lysis buffer, was measured at a 570-nm wavelength. The optical density measurement of untreated N2a cells was assumed to be $100 \%$ for analysis of cell viability.

\section{Statistical Considerations}

Statistical analysis was performed using one-way analysis of variance (ANOVA) in order to determine the statistical significance between untreated (control) group, and experimental groups (N2a cells treated with herbicides alone, and N2a cells pretreated with mitochondria-targeted antioxidant, SS31 and then treated with herbicides) for the total RNA content, and cell viability. A permutation analysis was conducted in order to determine statistical significance between untreated (control) group, and experimental groups for total RNA content and cell viability.

\section{Results}

Total RNA content: To determine whether picloram or triclopyr affected the total RNA content, we treated 0.5 million $\mathrm{N} 2 \mathrm{a}$ cells with picloram ( $5 \mathrm{mM}$ final concentration) and triclopyr ( $3 \mathrm{mM})$ for $48 \mathrm{~h}$ each and compared their total RNA content with that in equal numbers of untreated cells. We isolated total RNA content 4 times individually and calculated the mean total RNA for comparison. As shown in Table 2, we found significantly decreased total RNA content in the N2a cells treated with picloram ( $\mathrm{P}<0.0001)$ and triclopyr $(\mathrm{P}<0.0001)$ compared to the untreated N2a cells (Table 2). However, in cells pretreated with SS31 and then treated with picloram, total RNA content was decreased $(\mathrm{P}<0.0001)$ compared to untreated cells. In the $\mathrm{N} 2 \mathrm{a}$ cells treated with only SS31, we found significantly increased total RNA content compared to the untreated N2a cells (Table 2). As shown in Table 2, $29.2 \mu \mathrm{g}$ of total RNA was found in the untreated N2a cells, and total RNA increased to $32.1 \mu \mathrm{g}$ in the N2a treated with SS31 $(\mathrm{P}<0.002)$.

Table 2. The total RNA content in mouse neuroblastoma (N2a) cells pretreated with SS31 and then treated with picloram and triclopyr.

\begin{tabular}{|l|c|c|c|c|}
\hline & Mean Total RNA (in $\mu \mathrm{g})$ & SE & Difference & Dunnett p-value \\
\hline Untreated N2a & 29.3 & 0.45 & & \\
\hline Picloram & 12.7 & 0.45 & -16.60 & $<0.0001$ \\
\hline SS31 + picloram & 23.6 & 0.45 & -5.67 & $<0.0001$ \\
\hline Triclopyr & 9.2 & 0.45 & -20.09 & $<0.0001$ \\
\hline SS31 + triclopyr & 20.0 & 0.45 & -9.3 & $<0.0001$ \\
\hline SS31 & 32.0 & 0.45 & 2.65 & 0.0023 \\
\hline
\end{tabular}

Note: One-way ANOVA was used to compare neurons treated with the herbicides and those that were not treated. Exact p-values are provided. These p-values were obtained using permutation tests. Dunnett's multiple comparison procedures with the untreated group as a control was used to adjust an experiment-wise error rate. Since we designed the study to compare each herbicide-treated group to the untreated group, we used Dunnett's multiple comparison adjustment to compare each treatment to the control. 
Cell viability: To determine whether picloram and triclopyr are toxic to N2a cells and decrease cell viability, we used the MTT assay to analyze N2a cells treated with the herbicides and also N2a cells pretreated with SS31 and then treated with the herbicides. As shown in Table 3, cell viability was significantly decreased in the $\mathrm{N} 2$ a cells treated with picloram $(\mathrm{P}<0001)$, and triclopyr $(\mathrm{P}<0.0001)$ compared to the untreated N2a cells. However, in the N2a cells pretreated with SS31 and then treated with the herbicides, cell viability was rescued by greater extent. In N2a cells pretreated with SS31 and no subsequent treatment, cell viability significantly increased $(\mathrm{P}<0.0001)$, compared to untreated N2a cells.

Table 3. Cell viability of mouse neuroblastoma cells pretreated with SS31 and then treated with picloram and triclopyr.

\begin{tabular}{|l|c|c|c|c|}
\hline & Mean optical density of MTT assay solution & SE & Difference & Dunnett p-value \\
\hline Untreated N2a & 1.27 & 0.0266 & & \\
\hline Picloram & 0.66 & 0.0266 & -0.61 & $<0.0001$ \\
\hline SS31 + picloram & 0.72 & 0.0266 & -0.54 & $<0.0001$ \\
\hline Triclopyr & 0.66 & 0.0266 & -0.60 & $<0.0001$ \\
\hline SS31 + triclopyr & 0.72 & 0.0266 & -0.54 & $<0.0001$ \\
\hline SS31 & 1.36 & 0.0266 & 0.09 & 0.1119 \\
\hline
\end{tabular}

Note: Same note as in Table 2.

mRNA expression of mitochondrial-encoded genes in N2a cells treated with herbicides: As shown in Table 4, mRNA expression of mitochondrially encoded genes decreased for all genes in the N2a cells that were treated with picloram and triclopyr. However, in the N2a cells that were first pretreated with SS31 and then treated with picloram and triclopyr, mRNA expression levels were higher.

Among all mitochondrial-encoded genes that we studied, the complex I gene (NADH-subunit 1) decreased the most, followed by the complex V gene (ATPase6), then the complex IV gene (COX1), and lastly, the complex III gene (Cyt. B) in the N2a cells treated with herbicides. Among these herbicides, we found that mRNA expression of the mitochondrial encoded genes decreased the most in $\mathrm{N} 2$ a cells treated with picloram, suggesting that picloram is more toxic to N2a cells. This decrease may have been the result of over-compensation by the increase in mRNA levels of the mitochondrial-encoded genes in N2a cells pretreated with SS31 and then further treated with herbicides. Overall, our findings of mRNA expression of mitochondria-encoded genes concurred with results of total RNA content and N2a cell viability.

mRNA expression of antioxidant enzyme proteins (peroxiredoxins) in N2a cells treated with the herbicides: We measured mRNA expression of antioxidant enzyme proteins and peroxiredoxins $1-6$ to determine the toxic effects of each of the two herbicides. We found decreased mRNA levels of Prx 1 (52\%), Prx3 (77\%), Prx3 (35\%), Prx4 (52\%), Prx5 (89\%), and Prx6 (7\%) in the N2a cells treated with picloram compared to untreated $\mathrm{N} 2 \mathrm{a}$ cells, indicating that picloram affects the mRNA expression of peroxiredoxins 1-6 (Table 4). However, in N2a cells pretreated with SS31 and then treated with picloram, we found that decreased mRNA levels of peroxiredoxins 1-6 increased to a greater extent (Table 4), suggesting that SS31 reduced the toxicity of picloram in N2a cells.

As shown in Table 4, in triclopyr-treated N2a cells, we found increased mRNA levels of Prx1 (by $12 \%), \operatorname{Prx} 2(70 \%), \operatorname{Prx} 3(30 \%)$, and $\operatorname{Prx} 4$ (41\%), indicating that triclopyr enhanced peroxiredoxins 
activity in N2a cells. We found unchanged the mRNA expressions of Prx4 and Prx6 in N2a cells treated triclopyr compared to the mRNA expressions in untreated N2a cells. However, in N2a cells pretreated with SS31 and then treated with triclopyr, we found increased mRNA expressions of Prx1 Prx2, Prx3, Prx4, and Prx 5 suggesting that SS31 boosted mitochondrial respiration in N2a cells.

mRNA expression of neuroprotective genes in $\mathrm{N} 2 \mathrm{a}$ cells treated with herbicides: We measured mRNA expression of the neuroprotective genes PGC1 $\alpha$, FOXO1, and NMDA in N2a cells treated with the herbicides only, and in N2a cells pretreated with SS31 and then treated with the herbicides.

As summarized in Table 4, in FOXO1, we found mRNA decreased by $68 \%$ in the picloram-treated cells and by $72 \%$ in the triclopyr-treated cells. In NMDAR, we found mRNA decreased by $50 \%$ in the picloram-treated cells and $79 \%$ in the triclopyr-treated cells. However, in N2a cells pretreated with SS31 and then treated with the herbicides, we found mRNA decreased in FOXO1 and NMDAR, suggesting that SS31 protected N2a cells from herbicide toxicity.

In N2a cells treated with picloram and triclopyr, mRNA expression in PGC1 $\alpha$ was higher than the mRNA expression in the untreated $\mathrm{N} 2 \mathrm{a}$ cells, indicating that herbicides did not influence the expression of mRNA in PGC1 $\alpha$. In N2a cells pre-treated with SS31, mRNA expression was higher suggesting that SS31 enhanced PGC1 $\alpha$ levels and boosted overall mitochondrial function.

Table 4. Differences in mRNA fold changes in N2a cells pretreated with SS31 and then treated with picloram and triclopyr (SYBR-Green chemistry based on quantitative real-time RT-PCR).

\begin{tabular}{|c|c|c|c|c|c|}
\hline Marker & \begin{tabular}{|l|} 
N2a cells \\
treated with \\
picloram
\end{tabular} & $\begin{array}{l}\text { N2a cells pretreated } \\
\text { with SS31 and then } \\
\text { treated with picloram }\end{array}$ & $\begin{array}{l}\text { N2a cells } \\
\text { treated with } \\
\text { triclopyr }\end{array}$ & $\begin{array}{l}\text { N2a cells pretreated } \\
\text { with SS31 and then } \\
\text { treated with triclopyr }\end{array}$ & \begin{tabular}{|l|} 
N2a cells \\
treated with \\
SS31 \\
\end{tabular} \\
\hline \multicolumn{6}{|c|}{ Antioxidants enzyme proteins (peroxiredoxins) } \\
\hline Prx1 & $0.48(52 \% \Downarrow)$ & $0.79(21 \% \Downarrow)$ & $1.12(12 \% \Uparrow)$ & $1.37(37 \% \Uparrow)$ & $1.20(20 \% \Uparrow)$ \\
\hline $\operatorname{Prx} 2$ & $0.23(77 \% \Downarrow)$ & $1.16(16 \% \Uparrow)$ & $1.7(70 \% \Uparrow)$ & $2.03(103 \% \Uparrow)$ & $1.10(10 \% \Uparrow)$ \\
\hline Prx3 & $0.35(65 \% \Downarrow)$ & $0.69(31 \% \Downarrow)$ & $1.3(30 \% \Uparrow)$ & $1.71(71 \% \Uparrow)$ & 1.00 \\
\hline Prx4 & $0.52(52 \% \Downarrow)$ & 0.90 & 0.99 & $2.01(101 \% \Uparrow)$ & $1.25(25 \% \Uparrow)$ \\
\hline Prx5 & $0.11(89 \% \Downarrow)$ & $0.37(63 \% \Downarrow)$ & $1.41(41 \% \Uparrow)$ & $1.48(48 \% \Uparrow)$ & $1.40(40 \% \Uparrow)$ \\
\hline Prx6 & 0.93 & $1.12(12 \% \Uparrow)$ & 1.02 & 0.93 & $1.30(30 \% \Uparrow)$ \\
\hline \multicolumn{6}{|c|}{ Neuroprotective genes } \\
\hline PGC1 $\alpha$ & $1.56(56 \% \Uparrow)$ & $1.55(55 \% \Uparrow)$ & $1.45(45 \% \Uparrow)$ & $1.89(89 \% \Uparrow)$ & $2.75(175 \% \Uparrow)$ \\
\hline FOXO1 & $0.32(68 \% \Downarrow)$ & $0.52(48 \% \Downarrow)$ & $0.28(72 \% \Downarrow)$ & $0.93(7 \% \Downarrow)$ & $0.45(55 \% \Downarrow)$ \\
\hline NMDAR & $0.50(50 \% \Downarrow)$ & $0.65(35 \% \Downarrow)$ & $0.21(79 \% \Downarrow)$ & 0.93 & $0.89(11 \% \Downarrow)$ \\
\hline \multicolumn{6}{|c|}{ Mitochondrial electron transport chain genes } \\
\hline NADH sub1 & $0.13(87 \% \Downarrow)$ & $0.22(78 \% \Downarrow)$ & $0.20(80 \% \downarrow)$ & $0.36(64 \% \Downarrow)$ & 0.93 \\
\hline Cyt. B & $0.54(46 \% \Downarrow)$ & $0.69(31 \% \Downarrow)$ & $0.74(26 \% \Downarrow)$ & $0.98(2 \% \Downarrow)$ & $1.94(94 \% \Uparrow)$ \\
\hline COX1 & $0.40(60 \% \Downarrow)$ & $0.75(25 \% \Downarrow)$ & $0.72(28 \% \downarrow)$ & $1.14(14 \% \Uparrow)$ & 0.93 \\
\hline ATP-6 & $0.39(61 \% \Downarrow)$ & $0.58(42 \% \Downarrow)$ & $0.57(43 \% \Downarrow)$ & $0.89(11 \% \Downarrow)$ & $1.11(11 \% \Uparrow)$ \\
\hline
\end{tabular}

Note: 1 fold mRNA expression means no change between experimental samples (N2a cells treated with picloram and triclopyr, N2a cells pretreated with SS31 and then treated with picloram and triclopyr, and N2a cells pretreated with only SS31) versus untreated N2a cells.

$>1$ fold mRNA expression indicates increased mRNA in untreated N2a cells.

$<1$ fold mRNA expression indicates decreased mRNA in untreated N2a cells. 
Herbicides and SS31 in primary neurons. To determine the toxicity of picloram and triclopyr, we treated 7-day-old (or 7 DIV) primary neurons with picloram and triclopyr for $48 \mathrm{~h}$ and then studied the neuronal morphology using phase-contrast light microscopy. As shown in Figure 2, we found decreased neuronal branching and networks, and degenerated neurons in these primary neurons, compared to the neuronal morphology in the untreated primary neurons, indicating that picloram and triclopyr damage neuronal morphology. In contrast, the SS31-treated primary neurons showed increased neuronal branching and networks relative to the untreated primary neurons, suggesting that SS31 has the capacity to enhance neuronal viability.

To determine if SS31 protected cells against the toxicity of picloram and triclopyr on neuronal morphology, we pretreated primary neurons with SS31 and then treated them with picloram and triclopyr. As shown in Figure 3, those neurons pretreated with SS31 and then treated with triclopyr or picloram did not exhibit degeneration, indicating that SS31 prevents the toxicity of herbicides, picloram and triclopyr.

Figure 2. Primary neurons from C57BL/6 mice treated with picloram (C), triclopyr (D) and SS31 (B). The neurons treated with picloram (C) and triclopyr (D) exhibited damaged morphology: a loss of projections and network, compared to the untreated neurons (A). The neurons that were treated with SS31 (B) showed increased neuronal branching and network. Image a shows cortical neurons and photographs taken using phase-contrast microscope at 20x the original magnification. Image $\mathbf{b}$ shows immunofluorescence analysis of beta III tubulin antibody in hippocampal neurons treated with $1 \mathrm{nM}$ SS31 (B), $5 \mathrm{mM}$ picloram (C), and $3 \mathrm{mM}$ triclopyr (D). Photographs were taken using fluorescence microscope at $100 x$ the original magnification. Green arrows indicate intact/healthy neurons, and white arrows, degenerative neurons.
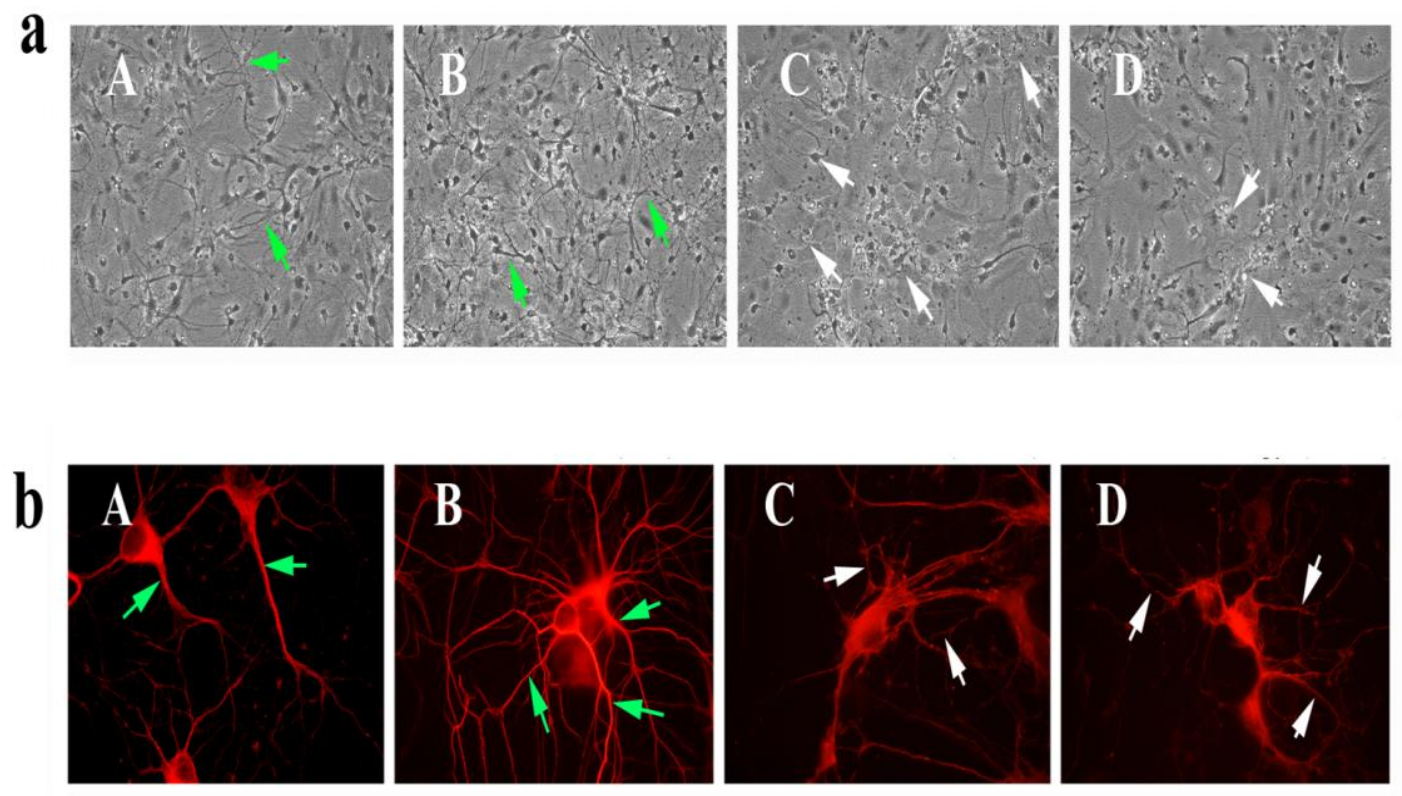
Figure 3. Primary neurons from mice pretreated with SS31 and then with picloram (B) and triclopyr (C). The neurons exhibited intact projections/network, similar to those in the untreated neurons (A). Image a shows primary cortical neurons and photographs taken with a phase-contrast microscope at 20x the original magnification. Image b shows immunofluorescence analysis of the beta III tubulin antibody in primary hippocampal neurons pretreated with $1 \mathrm{nM} \mathrm{SS} 31$ and then treated with $5 \mathrm{mM}$ picloram (B) and $3 \mathrm{mM}$ triclopyr (C). Pretreatment with SS31 prevented neuronal damage caused by picloram and triclopyr. Photographs were taken using a fluorescence microscope at 100x the original magnification. Green arrows indicate intact/healthy neurons, and white arrows, degenerative neurons.
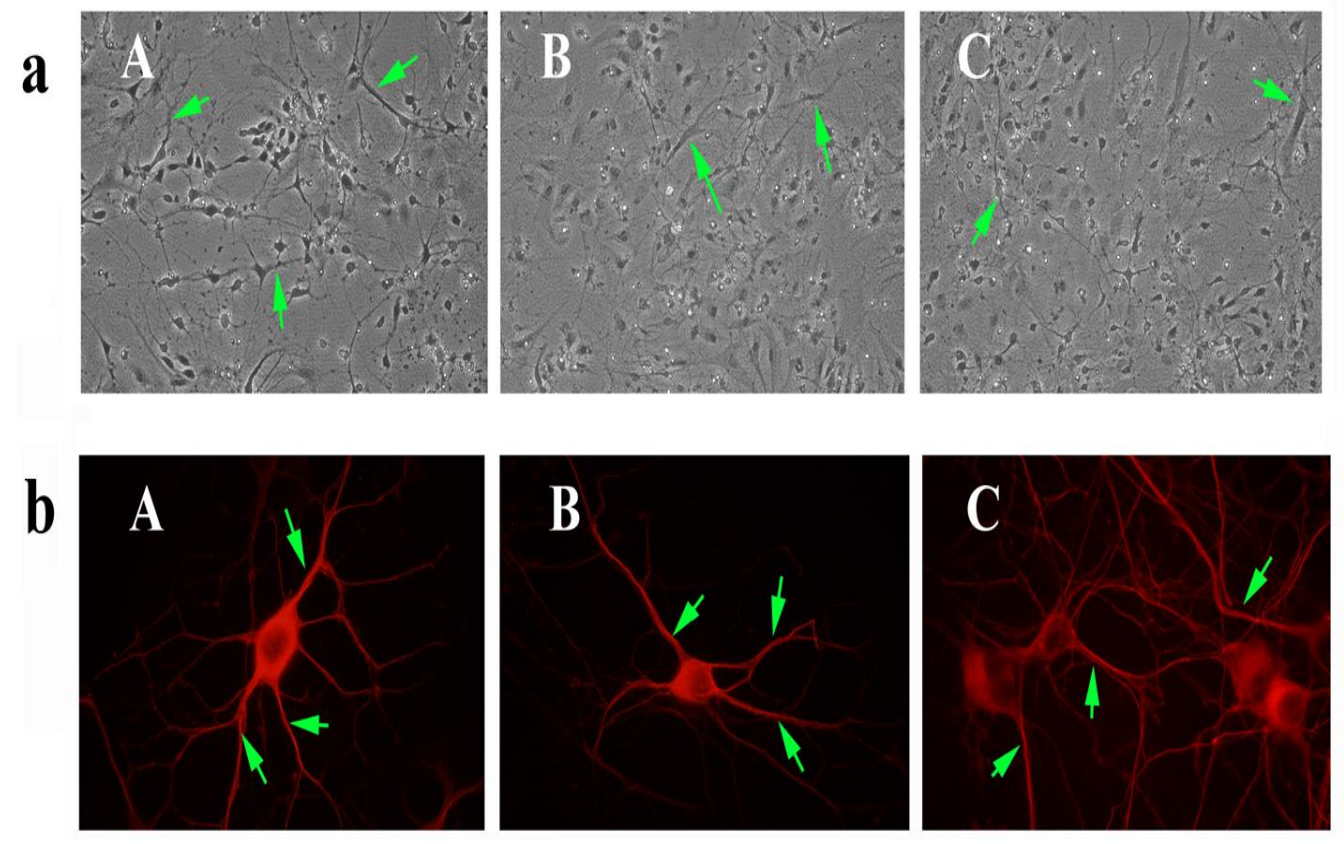

Immunofluorescence analysis using herbicides and SS31 in primary neurons. To determine neuronal morphology in primary hippocampal neurons exposed to picloram and triclopyr, we conducted immunofluorescence analysis using the cytoskeletal protein beta III tubulin antibody. We found decreased neuronal network and degenerating neurons in neurons treated with picloram and triclopyr. In contrast, in primary hippocampal neurons that we pretreated with SS31, and then treated with picloram and triclopyr, we found neuronal network and viability of neurons that resembled those of untreated neurons.

\section{Discussion}

We found significantly decreased total RNA content and decreased cell viability in N2a cells treated with picloram and triclopyr, compared total RNA content and cell viability in the untreated N2a cells. However, in the N2a cells that we first pretreated with SS31 and then treated with picloram and triclopyr, total RNA content and cell viability were basically not decreased, suggesting that SS31 had a neuroprotective effect against herbicide toxicity, thus preventing neuronal damage. Primary neurons that were treated with picloram and triclopyr showed losing network and signs of degeneration. 
However, primary neurons that were pretreated with SS31 and then treated with picloram and triclopyr showed increased neuronal networks. Thus, picloram and triclopyr damaged neuronal cells that were not when neurons were pretreated with SS31, indicating that SS31 protects neuronal cells against herbicides toxicity.

Decreased cell viability in N2a cells treated with the herbicides: Mitochondrial respiration is a good measure to assess cell viability, particularly when cells under stress or exposed to toxins. Using MTT assay, we measured mitochondrial respiration in N2a cells treated with the herbicides, and found that the N2a cells treated with picloram and triclopyr showed decreases in mitochondrial respiration, indicating that the herbicides affect cell mitochondrial respiration (cell viability). However, in cells pretreated with SS31 and then treated with the herbicides, cell viability was increased greater extent - indicating that SS31 is capable of decreasing mitochondrial toxicity caused by herbicides. It is also interesting to observe that cells treated with only SS31 showed increased cell viability-suggesting that SS31 does not just prevent herbicide toxicity but also enhances mitochondrial respiration probably by decreasing free radicals and oxidative damage [35].

Decreased mitochondrial-encoded gene expression in N2a cells treated with the herbicides: We measured the mRNA expression of mitochondrial-encoded genes in herbicide-treated and herbicide-untreated N2a cells to determine cell vitality since mitochondrial gene expressions are good indicators of energy in the cell mitochondrial metabolism [36]. Further, we also investigated the mRNA expression of mitochondrial-encoded genes to determine whether the mitochondria-targeted antioxidant SS31 increases mitochondrial activity in cells treated with SS31 and the herbicides. We found mRNA expression of mitochondrial-encoded genes decreased in N2a cells treated with the herbicides. Interestingly, we found complex 1 and complex $\mathrm{V}$ genes were down-regulated the most among all mitochondrial complexes studied, suggesting that complexes 1 and $\mathrm{V}$ are affected the most by the herbicides. In N2a cells pretreated with SS31, mitochondrial gene expressions were compensated for, to a large extent, suggesting that SS31 decreases mitochondrial free radicals and increases mitochondrial activity and function [29,35,37].

Decreased mRNA expression of genes that encode antioxidant enzyme proteins in N2a cells treated with the herbicides: The purpose of measuring mRNA in N2a cells was to determine the activity of antioxidant enzyme proteins in cells treated with picloram and triclopyr. As described earlier, herbicides have mutagenic, carcinogenic, and teratogenic properties. However, their toxicity levels on neurons are less known. In the present study, we found decreased mRNA expression of peroxiredoxins in neurons treated with picloram. In triclopyr treated cells, we found unchanged or increased levels of the mRNA expression of peroxiredoxins. However, overall, neurons pretreated with SS31 and then treated with an herbicide showed increased levels of mRNA expression of antioxidant enzyme proteins.

Peroxiredoxins are a group of antioxidant enzymes present in all organisms. These antioxidant enzymes protect cells by regulating redox, phosphorylation, and oligomerization in cells [38]. There are 6 isoforms of peroxiredoxins ( $\operatorname{Prx} 1-6$ ), and they neutralize $\mathrm{H}_{2} \mathrm{O}_{2}$ and participate in decreasing oxidative damage, which protects cells from various toxic insults. Peroxiredoxins are classified into three categories based on the position of the cystein and its number: (1) typical 2-Cys Prxs; (2) atypical 2-Cys Prxs; and (3) 1-Cys Prxs. These enzymes share the same basic catalytic mechanism, in which a redox-active cysteine in the active site is oxidized to a sulfenic acid by the peroxide substracter [38]. 
The relative abundance of Prx enzymes in mammalian cells appears to protect cellular components by reducing levels of peroxides in cells.

In the present study, we found decreased mRNA levels of peroxiredoxins 1-6 in the N2a cells treated with picloram, suggesting that picloram affects the mRNA expression of endogenous antioxidant enzymes, peroxiredoxins. In contrast, we found unchanged or slightly increased, the mRNA expression of peroxiredoxins in triclopyr-treated N2a cells, suggesting that used $3 \mathrm{mM}$ concentration of triclopyr does not affect peroxiredoxins expressions. It is possible that the concentrations that we used in treating $\mathrm{N} 2 \mathrm{a}$ cells for triclopyr $(3 \mathrm{mM})$ were too low to show an effect on mRNA expression, and at higher concentrations, they may decrease mRNA expression of peroxiredoxins. In the N2a cells pretreated with SS31 and then treated with the herbicides, we found increased mRNA levels for all peroxiredoxins, suggesting that SS31 decreases free radical production and mitochondrial oxidative damage, and enhances mitochondrial function and cell viability.

Very little is known about the role of peroxiredoxins in brain cells treated with herbicides. Our study is the first to describe the mRNA expression of peroxiredoxins in brain cells treated with picloram, and triclopyr. Further research is needed to understand the connection between increased mRNA expressions of peroxiredoxins in brain cells treated with picloram, in particular. In addition, further research is still needed to understand the mechanistic, biochemical link between herbicides and peroxiredoxins.

Decreased expression of neuroprotective genes in N2a cells treated with the picloram and triclopyr: We measured mRNA in N2a cells treated with picloram and triclopyr and in untreated N2a cells to determine the neurotoxic effects of the herbicides. Although there are several neuroprotective genes in the genome, we selected PGC1 $\alpha$, NMDAR, and FOXO1 genes to study since they represent neuroprotection and determine the viability of the neuron. We found decreased mRNA expression of the 3 neuroprotective genes from the $\mathrm{N} 2 \mathrm{a}$ cells that we had treated with the 2 herbicides. However, neurons treated with SS31, or pretreated SS31 and then treated with one of the herbicides showed increased expression of neuroprotective genes.

$\underline{\text { PGC- } 1 \alpha}$. This transcription co-activator interacts with a range of transcription factors involved in a wide variety of biological responses, including adaptive thermogenesis and mitochondrial biogenesis of several tissues, such as brain tissues [39]. The overexpression of PGC1 $\alpha$ was found to protect mammalian cells, including neurons, from mitochondrial oxidative damage by mediating gene expressions of transcription factors. Recently, lower-than-normal levels of PGC-1 $\alpha$ expression were found in elderly persons and elderly persons with neurodegenerative diseases such as Alzheimer's [40], and Huntington's [41-43]. The connection between herbicide toxicity of neurons and PGC-1 $\alpha$ expression is unknown. In the present study, we found PGC-1 $\alpha$ expression is not affected by the low molar concentration of the herbicides. However, in N2a cells pretreated with SS31 and then treated with herbicides, PGC1 $\alpha$ expression increased for each of the two herbicides, suggesting that SS31 boosts mitochondrial function and cell viability.

FOXO1: FOXO1 is a fork head transcription factor of the FOXO subfamily, which plays an important role in cellular differentiation, proliferation, and metabolism [2,44-46]. A widely held theory is that chronic exposure of cells to elevated glucose concentrations causes a deterioration of $\beta$ cell function. Glucose toxicity is thought to arise as a consequence of chronic oxidative stress, when intracellular glucose concentrations exceed the glycolytic capacity of the $\beta$ cell. The over-expression of 
FOXO1 suppresses oxidative stress under hyperglycemia or abnormal glucose metabolism [47]. We found decreased mRNA expression of FOXO1 in the N2a cells that were treated with the herbicides, indicating that FOXO1 expression was affected by herbicides.

N-methyl-D-aspartate receptor (NMDA receptor): Recently, NMDAR activity in synapses was found to have neuroprotective effects by stimulating the antioxidant enzyme peroxiredoxin [48]. It is well-established that herbicides kill unwanted plants by inducing free radical production, mitochondrial damage, and cell death [17]. We found NMDAR expression was decreased in cells treated with herbicides. However, in N2a cells pretreated with SS31 and then treated with the herbicides, decreased NMDAR mRNA expression increased to some extent, suggesting that SS31 decreases free radical production and oxidative damage in cells It is possible that humans exposed to these herbicides may have adverse effects due to the effects of herbicides on free radicals and cell vitality.

Decreased total RNA content in N2a cells treated with herbicides and altered expression of peroxiredoxins and electron transport chain genes: As described earlier, the total RNA content was decreased in cells treated with herbicides, picloram and triclopyr, and this decreased total RNA content may be responsible for decreased mRNA expression of antioxidant enzymes, peroxiredoxins $1-6$, in cells treated with picloram and triclopyr. These findings clearly suggest that herbicides are toxic and influence mRNA expressions of peroxiredoxins. However, in cells pretreated with SS31 and then treated with herbicides, picloram and triclopyr the total RNA content was increased relative to picloram and triclopyr treated cells (Table 2), indicating that SS31 decrease cell toxicity and increase the total RNA content. This is truly reflected in our real-time PCR analysis of mRNA expression levels of peroxiredoxins 1-6, and electron transport chains genes (Table 4), suggesting that SS31 is protective against cell toxicity caused by herbicides, picloram and triclopyr.

Primary neuronal cultures, herbicides and SS31: Our primary hippocampal neurons that we treated with picloram and triclopyr exhibited decreased neuronal branching and networks, and degenerating neurons. However, primary neurons treated with SS31 exhibited increased neuronal network and neuronal branching indicating SS31 has capability to decrease oxidative insults, and enhance neuronal viability. Further, in primary neurons, SS31 has increased neuronal network and branching, and in neurons pretreated with SS31, SS31 prevented neuronal damage caused by herbicides. These findings are in agreement with our previous observations that primary neurons from amyloid beta precursor protein transgenic mice were protected against amyloid beta toxicity when treated with SS31 [30]. In addition, SS31 increased RNA content, cell viability, and mRNA expression of endogenous antioxidant enzymes, peroxiredoxins in N2a cells. These results are consistent with SS31, which is known to decrease and to neutralize free radicals, and to protect neurons from oxidative insults. Overall, findings from our study suggest that SS31 is neuroprotective and may have therapeutic value against the toxicity of commonly used herbicides in an agriculture sector.

\section{Acknowledgements}

This research was supported by NIH grants AG028072, AG026051, RR00163 and S10RR024585, Alzheimer Association grant IIRG-09-92429, Vertex Pharmaceuticals, and Medivation, Inc. 


\section{References}

1. Colborn, T.; Short, P. Pesticide use in the U.S. and policy implications: A focus on herbicides. Toxicol. Ind. Health 1999, 15, 241-276.

2. Arbuckle, T.E.; Burnett, R.; Cole, D.; Teschke, K.; Dosemeci, M.; Bancej, C.; Zhang, J. Predictors of herbicide exposure in farm applicators. Int. Arch. Occup. Environ. Health. 2002, 75, 406-414.

3. Arbuckle, T.E.; Lin, Z.; Mery, L.S. An exploratory analysis of the effect of pesticide exposure on the risk of spontaneous abortion in an Ontario farm population. Environ. Health Perspect. 2001, 109, 851-857.

4. Arbuckle, T.E.; Savitz, D.A.; Mery, L.S.; Curtis, K.M. Exposure to phenoxy herbicides and the risk of spontaneous abortion. Epidemiology 1999, 10, 752-760.

5. Bhanti, M.; Taneja, A. Contamination of vegetables of different seasons with organophosphorous pesticides and related health risk assessment in northern India. Chemosphere 2007, 69, 63-68.

6. Bullman, T.A.; Kang, H.K. The effects of mustard gas, ionizing radiation, herbicides, trauma, and oil smoke on US military personnel: the results of veteran studies. Annu. Rev. Public Health 1994, 15, 69-90.

7. Green, R.M.; Abdelghani, A. Effects of long-term exposure of the red swamp crawfish Procambarus clarkii to a mixture of two herbicides, 2,4-dichlorophenoxyacetic acid and monosodium methanearsonate, and associated human health risks. Int. J. Environ. Res. Public Health 2004, 1, 124-131.

8. Kaioumova, D.F.; Khabutdinova, L.K.H. Cytogenetic characteristics of herbicide production workers in Ufa. Chemosphere 1998, 37, 1755-1759.

9. Kavlock, R.; Cummings, A. Mode of action: reduction of testosterone availability-molinate-induced inhibition of spermatogenesis. Crit. Rev. Toxicol. 2005, 35, 685-690.

10. Martin, S.A., Jr.; Sandler, D.P.; Harlow, S.D.; Shore, D.L.; Rowland, A.S.; Alavanja, M.C. Pesticide use and pesticide-related symptoms among black farmers in the Agricultural Health Study. Am. J. Ind. Med. 2002, 41, 202-209.

11. Moran, J.M.; Gonzalez-Polo, R.A.; Ortiz-Ortiz, M.A.; Niso-Santano, M.; Soler, G.; Fuentes, J.M.; Identification of genes associated with paraquat-induced toxicity in SH-SY5Y cells by PCR array focused on apoptotic pathways. J. Toxicol. Environ. Health A 2008, 71, 1457-1467.

12. Salehi F.; Dunfield L.; Phillips K.P.; Krewski D.; Vanderhyden B.C. Risk factors for ovarian cancer: an overview with emphasis on hormonal factors. J. Toxicol. Environ. Health B Crit. Rev. 2008, 11, 301-321.

13. Johannessen, J.N.; Markey, S.P. Assessment of the opiate properties of two constituents of a toxic illicit drug mixture. Drug Alcohol. Depend. 1984, 13, 367-374.

14. Carney, E.W.; Billington, R.; Barlow, S.M. Developmental toxicity evaluation of triclopyr butoxyethyl ester and triclopyr triethylamine salt in the CD rat. Reprod. Toxicol. 2007, 23, 165-174.

15. Dann, R.L.; Close, M.E.; Lee, R.; Pang, L. Impact of data quality and model complexity on prediction of pesticide leaching. J. Environ. Qual. 2006, 35, 628-640. 
16. Eyheraguibel, B.; ter Halle, A.; Richard, C. Photodegradation of Bentazon, Clopyralid, and Triclopyr on model leaves: Importance of a systematic evaluation of pesticide photostability on crops. J. Agric. Food Chem. 2009, 57, 4810-4817.

17. Grossmann, K.; Kwiatkowski, J.; Tresch, S. Auxin herbicides induce $\mathrm{H}_{2} \mathrm{O}_{2}$ overproduction and tissue damage in cleavers (Galium aparine L.). J. Exp. Bot. 2001, 52, 1811-1816.

18. Horsman, J.; McLean, M.D.; Olea-Popelka, F.C.; Hall, J.C. Picloram resistance in transgenic tobacco expressing an anti-picloram scFv antibody is due to reduced translocation. J. Agric. Food Chem. 2007, 55, 106-112.

19. Mohammed, K.B.; Ma, T.H. Tradescantia-micronucleus and -stamen hair mutation assays on genotoxicity of the gaseous and liquid forms of pesticides. Mutat. Res. 1999, 426, 193-199.

20. Steinmacher, D.A.; Krohn, N.G.; Dantas, A.C.; Stefenon, V.M.; Clement, C.R.; Guerra, M.P. Somatic embryogenesis in peach palm using the thin cell layer technique: Induction, morpho-histological aspects and AFLP analysis of somaclonal variation. Ann. Bot. 2007, 100, 699-709.

21. Tran, A.T.; Hyne, R.V.; Doble, P. Determination of commonly used polar herbicides in agricultural drainage waters in Australia by HPLC. Chemosphere 2007, 67, 944-953.

22. Woudneh, M.B.; Sekela, M.; Tuominen, T.; Gledhill, M. Acidic herbicides in surface waters of Lower Fraser Valley, British Columbia, Canada. J. Chromatogr. A. 2007, 1139, 121-129.

23. Mayes, M.A.; Hopkins, D.L.; Dill, D.C. Toxicity of picloram (4-amino-3,5,6-trichloropicolinic acid) to life stages of the rainbow trout. Bull. Environ. Contam. Toxicol. 1987, 38, 653-660.

24. Young, A.L. A conflict between science and social concerns: Agent Orange. Environ. Sci. Pollut. Res. Int. 2008, 15, 1-2.

25. Reuber, M.D. Carcinogenicity of picloram. J. Toxicol. Environ. Health 1981, 7, 207-222.

26. Hotchkiss, S.A.; Hewitt, P.; Caldwell, J.; Chen, W.L.; Rowe, R.R. Percutaneous absorption of nicotinic acid, phenol, benzoic acid and triclopyr butoxyethyl ester through rat and human skin in vitro: Further validation of an in vitro model by comparison with in vivo data. Food Chem. Toxicol. 1992, 30, 891-899.

27. Szeto, H.H. Cell-permeable, mitochondrial-targeted, peptide antioxidants. AAPS J. 2006, 8, E277-E283.

28. Szeto, H.H. Mitochondria-targeted peptide antioxidants: novel neuroprotective agents. AAPS J. 2006, 8, E521-E531.

29. Szeto, H.H. Development of mitochondria-targeted aromatic-cationic peptides for neurodegenerative diseases. Ann. N. Y. Acad. Sci. 2008, 1147, 112-121.

30. Manczak, M.; Mao, P.; Calkins, M.J.; Cornea, A.; Reddy, A.P.; Murphy, M.P.; Szeto, H.H.; Park, B.; Reddy, P.H. Mitochondria-targeted antioxidants protect against amyloid-beta toxicity in Alzheimer's disease neurons. J. Alzheimers Dis. 2010, 20, S609-S631.

31. Manczak, M.; Park, B.S.; Jung, Y.; Reddy, P.H. Differential expression of oxidative phosphorylation genes in patients with Alzheimer's disease: implications for early mitochondrial dysfunction and oxidative damage. Neuromol. Med. 2004, 5, 147-162.

32. Mosmann, T. Rapid colorimetric assay for cellular growth and survival: application to proliferation and cytotoxicity assays. J. Immunol. Method. 1983, 65, 55-63. 
33. Giorgetti, S.; Raimondi, S.; Cassinelli, S.; Bucciantini, M.; Stefani, M.; Gregorini, G.; Albonico, G.; Moratti, R.; Montagna, G.; Stoppini, M.; Bellotti, V. Beta2-Microglobulin is potentially neurotoxic, but the blood brain barrier is likely to protect the brain from its toxicity. Nephrol. Dial. Transplant. 2009, 24, 1176-1181.

34. Mao, P.; Ardeshiri, A.; Jacks, R.; Yang, S.; Hurn, P.D.; Alkayed, N.J. Mitochondrial mechanism of neuroprotection by CART. Eur. J. Neurosci. 2007, 26, 624-632.

35. Reddy, P.H. Mitochondrial dysfunction in aging and Alzheimer's disease: strategies to protect neurons. Antioxid Redox Signal 2007, 9, 1647-1658.

36. Manczak, M.; Jung, Y.; Park, B.S.; Partovi, D.; Reddy, P.H. Time-course of mitochondrial gene expressions in mice brains: implications for mitochondrial dysfunction, oxidative damage, and cytochrome c in aging. J. Neurochem. 2005, 92, 494-504.

37. Reddy, P.H. Mitochondrial medicine for aging and neurodegenerative diseases. Neuromol. Med. 2008, 10, 291-315.

38. Rhee, S.G.; Chae, H.Z.; Kim, K. Peroxiredoxins: a historical overview and speculative preview of novel mechanisms and emerging concepts in cell signaling. Free Radic. Biol. Med. 2005, 38, 1543-1552.

39. Liang, H.; Ward, W.F. PGC-1alpha: A key regulator of energy metabolism. Adv. Physiol. Educ. 2006, 30, 145-151.

40. Qin, W.; Haroutunian, V.; Katsel, P.; Cardozo, C.P.; Ho, L.; Buxbaum, J.D.; Pasinetti, G.M.; PGC-1alpha expression decreases in the Alzheimer disease brain as a function of dementia. Arch. Neurol. 2009, 66, 352-361.

41. Cui, L.; Jeong, H.; Borovecki, F.; Parkhurst, C.N.; Tanese, N.; Krainc, D. Transcriptional repression of PGC-1alpha by mutant huntingtin leads to mitochondrial dysfunction and neurodegeneration. Cell 2006, 127, 59-69.

42. St-Pierre, J.; Drori, S.; Uldry, M.; Silvaggi, J.M.; Rhee, J.; Jäger, S.; Handschin, C.; Zheng, K.; Lin, J.; Yang, W.; Simon, D.K.; Bachoo, R.; Spiegelman, B.M. Suppression of reactive oxygen species and neurodegeneration by the PGC-1 transcriptional coactivators. Cell 2006, 127, 397-408.

43. Weydt, P.; Pineda, V.V.; Torrence, A.E.; Libby, R.T.; Satterfield, T.F.; Lazarowski, E.R.; Gilbert, M.L.; Morton, G.J.; Bammler, T.K.; Strand, A.D.; Cui, L.; Beyer, R.P.; Easley, C.N.; Smith, A.C.; Krainc, D.; Luquet, S.; Sweet, I.R.; Schwartz, M.W.; La Spada, A.R. Thermoregulatory and metabolic defects in Huntington's disease transgenic mice implicate PGC-1alpha in Huntington's disease neurodegeneration. Cell Metab. 2006, 4, 349-362.

44. Birkenkamp, K.U.; Coffer, P.J. FOXO transcription factors as regulators of immune homeostasis: molecules to die for? J. Immunol. 2003, 171, 1623-1629.

45. Kaestner, K.H.; Knochel, W.; Martinez, D.E. Unified nomenclature for the winged helix/forkhead transcription factors. Genes Dev. 2000, 14, 142-146.

46. Nakae, J.; Kitamura, T.; Silver, D.L.; Accili, D. The forkhead transcription factor Foxo1 (Fkhr) confers insulin sensitivity onto glucose-6-phosphatase expression. J. Clin. Invest. 2001, 108, 1359-1367.

47. Gross, D.N.; van den Heuvel, A.P.; Birnbaum, M.J. The role of FoxO in the regulation of metabolism. Oncogene 2008, 27, 2320-2336. 
48. Papadia, S.; Soriano, F.X.; Léveillé, F.; Martel, M.A.; Dakin, K.A.; Hansen, H.H.; Kaindl, A.; Sifringer, M.; Fowler, J.; Stefovska, V.; McKenzie, G.; Craigon, M.; Corriveau, R.; Ghazal, P.; Horsburgh, K.; Yankner, B.A.; Wyllie, D.J.; Ikonomidou, C.; Hardingham, G.E. Synaptic NMDA receptor activity boosts intrinsic antioxidant defenses. Nat. Neurosci. 2008, 11, 476-487.

(C) 2011 by the authors; licensee MDPI, Basel, Switzerland. This article is an open access article distributed under the terms and conditions of the Creative Commons Attribution license (http://creativecommons.org/licenses/by/3.0/). 